\title{
Cortical arousal and two flash threshold
}

\author{
P. H. VENABLES AND L. A. WARWICK-EVANS \\ BIRKBECK COLLEGE, UNIVERSITY OF LONDON
}

Level of arousal as indicated by the amplitude of the EEG alpha rhythm was continuously recorded from $40 \mathrm{Ss}$ while their two flash thresholds were measured. A significant correlation $(r=+.56)$ found between the two variables was interpreted as supporting the theory that $2 \mathrm{FT}$ is a measure of arousal. Additional evidence from other sources is considered, and a reason why the correlation is not higher is offered.

Two flash threshold (2FT), (the longest interval between two flashes of light at which they are seen as one), has been used as a measure of cortical arousal in normal Ss, anxious patients, and schizophrenics (Venables \& Wing, 1962; Venables, 1963; Hume \& Claridge, 1965; Rose, 1966). Its use as such a measure has been suggested by experiments in which stimulation of the reticular formation has been shown to bring about an improvement in cortical resolution (Lindsley, 1958; Steriade \& Demetrescu, 1962; Schwartz \& Shagass, 1963). Little direct demonstration that two flash threshold is related to level of arousal has been made. Some support, however, has come from an experiment (Kopell, Noble, \& Silverman, 1965) showing that thiamylal and methamphetamine respectively raised and lowered 2 FT. A more direct check on the relation was provided in the present experiment by measuring 2FT while simultaneously recording a more widely accepted measure of cortical arousal, the amplitude of the alpha rhythm. A directly quantifiable measure of alpha amplitude was made by using a voltage-to-frequency converter (De Sa \& Molyneux, 1962) similar in function to the integrator used successfully by Goldstein, Sugerman, Stolberg, Murphree, \& Pfeiffer (1965). Method

Forty Ss were used: They were male and female university students and technicians. Their mean age was 23.0 years with a range from 18 to 39 years. The two flash presentation apparatus has already been described (Venables, 1963). The brightness of each flash was $160 \mathrm{ft}-\mathrm{L}$ and that of the fixation patch $0.04 \mathrm{ft}-\mathrm{L}$. S reported whether he saw the flashes as one or two by pressing a key once or twice.

A bilateral parieto-occipital placement of EEG electrodes was used, but only the signal from the right hand side was integrated, the left hand channel being used as a check on artifacts. The right hand channel and the output of the integrator were each recorded by separate pens of a Grass model 7 polygraph; other pens recorded the time of flash presentation and the untreated data from the left hand side. Data from the right side only were used in order to mini- mize interference from the right hand, which was used for responding. $S$ sat in a dark semi-soundproof room for $4 \mathrm{~min}$ before examples of the two flashes were presented in order to familiarize him with the procedure. The $2 \mathrm{FT}$ was then measured twice using the modified form of the constant method described by Venables (1963); the first and second measurements were separated by a $2 \mathrm{~min}$ interval. The number of pulses from the integrator were counted during the $5 \mathrm{sec}$ which preceded the flash presentations, by which the final value of the threshold was determined.

Results

The correlation between first and second thresholds was +.72 and between first and second pulse counts +.82 . The relation between the $2 \mathrm{FT}$ and the integrated EEG was examined on the basis of data averaged over the two occasions of testing.

The individual data and a linear regression line showing a relation between the two variables are plotted in Fig: 1. The correlation between the two variables $(r=+.56)$ was shown by analysis of variance

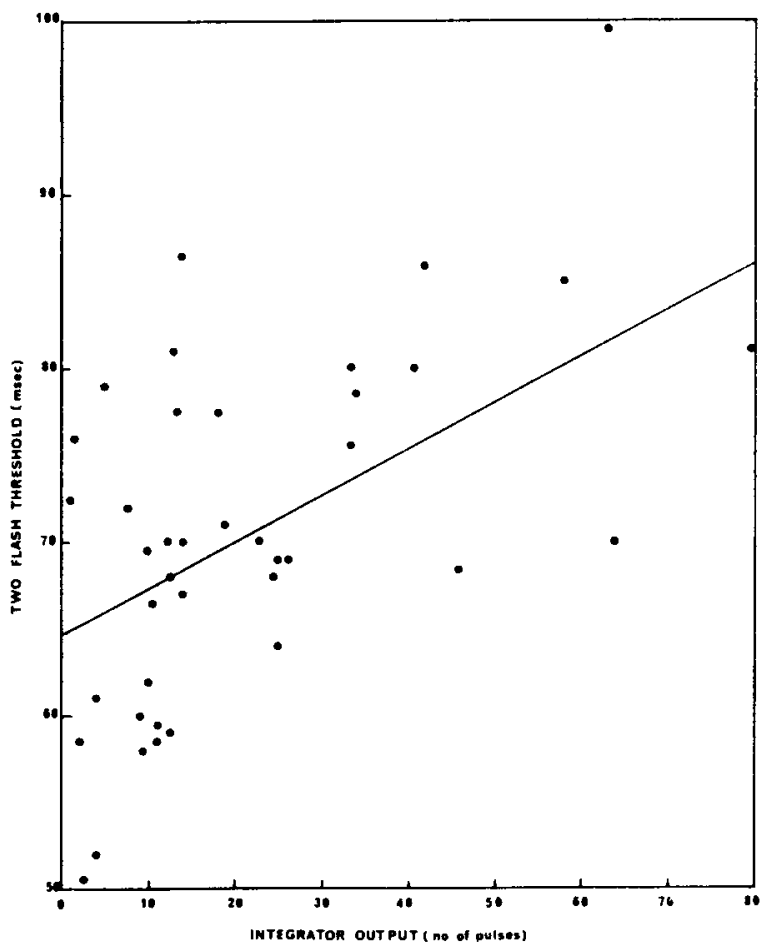

Fig. 1. Data for $40 \mathrm{Ss}$ relating two flash threshold to number of pulses from integrated EEG. Regression line $Y=.28 x+64.88$ (Integrator calibration, 2.6 pulses per $\mu \mathrm{V}$ peak to peak, with an arbitrary zero at $6 \mu \mathrm{V})$ 
to be significant $(F=3.86, d f=5 / 34, p<.01)$. It did not depart significantly from linearity $(F=0.8, \mathrm{df}=$ $4 / 34, \mathrm{~ns})$.

Discussion

The finding of a significant relation between $2 \mathrm{FT}$ and an EEG index gives support to studies which have tentatively used the 2FT as a measure of arousal. A decrease in alpha amplitude can reflect either an increase in arousal or a decrease to condition of very relaxed rest (Stennet, 1957), but it is reasonable to assume that the level of attention demanded by the two flash task was sufficient to avoid such a low level of arousal. This assumption was confirmed by the finding that the correlation between alpha amplitude and 2FT did not depart significantly from linearity.

That there was a wide variation in the amplitude of the alpha rhythm shown by different Ss is in itself of interest in that Adrian (1947) states that the alpha rhythm is always absent when the attention is directed to a visual stimulus. In the present experiment, $S$ was paying attention to a fixation patch, and yet high amplitude EEG was present for part of the time in many Ss.

Appropriate stimulation of the reticular formation results in desynchronization of the EEG (Moruzzi \& Magoun, 1949); it also facilitates the appearance of two cortical evoked potentials in response to two flashes where formerly only one potential had been evoked (Lindsley, 1957). Experiments suggest that the appearance of two evoked potentials in the visual cortex parallels the subjective experience of perceiving two flashes (Vaughan \& Costa, 1964). With these findings in mind, a high correlation between EEG signs of arousal and $2 \mathrm{FT}$ would be expected. One possible reason for the finding of only a moderate correlation is suggested by the work of Schwartz \& Shagass (1963), who show that evoked potential signs of cortical recovery functions are similar between resting and spontaneously aroused EEG states but dissimilar in the case of spontaneously aroused EEG states and aroused states caused by reticular stimulation. In the present experiment EEG arousal may on occasion occur spontaneously at a cortical level and on other occasions be the result of reticular activation. As the $2 \mathrm{FT}$ might be considered to be different in these two cases, the moderate size of the correlation between $2 \mathrm{FT}$ and integrated EEG is not unexpected.

\section{References}

Adrian, E. D. The physical background of perception. Oxford: Clarendon Press, 1947.

De'Sa, o., \& Molyneaux, L. A transistor voltage-to-frequency convertor. Electron: Eng., 1962, 34, 468-469.

Goldstein, L., Sugarman, A. A., Stolberg, H., Murphree, H. B., \& Pfeiffer, C. C. Electro-cerebral activity in schizophrenics and non-psychotic subjects: quantitative EEG analysis. EEG clin. Neurophysiol., 1965, 19, 350-361.

Hume, W. I., \& Claridge, G. S. A comparison of two measures of "arousal" in normal subjects. Life Science, 1965, 4, 545-553.

Kopell, B. S., Noble, E. P., \& Silverman, J. The effect of thiamylal and methamphetamine on the two-flash fusion threshold. Life Science, 1965, 4, 2211-2214.

Lindsley, D. B. Chapter 25. In H. H. Jasper et al (Eds.), Reticular formation of the brain. London: Churchill, 1957.

Moruzzi, G., \& Magoun, H. W. Brain stem reticular formation and activation of the EEG. EEG clin. Neurophysiol., 1949, 1, 455473.

Rose, R. T. Anxiety and arousal: A study of two-flash fusion and skin conductance. Psychon. Sci., 1966, 6, 81-82.

Stennet, R. G. The relationship of alpha amplitude to the level of palmar conductance. EEG clin. Neurophysiol., 1957, 9, 131-138.

Steriade, M., \& Demetruscu, M. Reticular facilitation of responses to acoustic stimuli. EEG clin. Neurophysiol., 1962, 14, 21-36.

Yaughan, H. G., \& Costa, L. D. Application of evoked potential techniques to behavioural investigation. Ann. N.Y. Acad. Sci. $1964,118,71-75$.

Venables, P. H. Selectivity of attention, withdrawal and cortical activation. Arch. Gen. Psychiat., 1963, 9, 74-78.

Venables, P. H., \& Wing, J. K. Level of arousal and the subclassification of schizophrenia. Arch. Gen. Psychiat., 1962. 7, 114-119.

\section{Notes}

1. The work described in this paper was supported by a grant from the Medical Research Council.

2. Thanks are due to Eric Sayer for constructing the equipment and to Catha Maslow for help in development of the experimental procedures. 